\title{
Interaction of selected platinum(II) complexes containing roscovitine-based CDK inhibitors as ligands with human liver microsomal cytochrome P450
}

\author{
Vlastimil Maseka,b, Pavel Starhac, Monika Harvanovaa, , Martina Michalova ${ }^{\mathrm{a}, \mathrm{b}}$, David Milde ${ }^{\mathrm{d}}$, Zdenek Travnicekc, \\ Eva Anzenbacherova ${ }^{e}$
}

Background. We studied the interaction of oxaliplatin derivatives involving cytotoxic adenine-based cyclin-dependent kinase inhibitors, with human liver microsomal cytochrome P450.

Methods and Results. The activities of 9 human liver microsomal CYP forms (CYPs 1A2, 7-ethoxyresorufin O-deethylation; 2A6, coumarin 7-hydroxylation; 2B6, 7-ethoxy-4-(trifluoromethyl) coumarin O-deethylation; $2 \mathrm{C} 8$, luciferin-6' methyl ether demethylation; 2C9, diclofenac 4'-hydroxylation, 6'-deoxyluciferin hydroxylation; 2C19, (S)mephenytoin 4'-hydroxylation; 2D6, bufuralol 1'-hydroxylation, 2E1, chlorzoxazone 6-hydroxylation; 3A4, testosterone $6 \beta$-hydroxylation, luciferin-6' benzyl ether debenzylation) were tested using HPLC, fluorescence and luminescence product detection. At $100 \mu \mathrm{M}$ platinum(II) oxalato complex concentration, CYP inhibition was in general $25 \%-50 \%$, except for the CYP3A4 form which showed roughly twice the inhibition (72\%-95\%). At low complex concentration $(10 \mu \mathrm{M})$, the difference in inhibition of CYP3A4 and other forms was even more pronounced. Dixon and LineweaverBurk plots indicated a partially noncompetitive mechanism of CYP3A4 inhibition.

Conclusions. The tested complexes significantly inhibit human liver microsomal CYP3A4 activity even at clinically relevant concentrations. This could be a serious drawback for the use of these compounds in clinical practice.

Key words: cytochrome P450, platinum(II) complexes, CDK inhibition, roscovitine derivatives

Received: January 10, 2014; Accepted with revision: May 29, 2014; Available online: July 4, 2014

http://dx.doi.org/10.5507/bp.2014.031

a Institute of Molecular and Translational Medicine, Faculty of Medicine and Dentistry, Palacky University Olomouc, Czech Republic ${ }^{b}$ Department of Pharmacology, Faculty of Medicine and Dentistry, Palacky University Olomouc

'Regional Centre of Advanced Technologies and Materials, Department of Inorganic Chemistry, Faculty of Science, Palacky University Olomouc

${ }^{d}$ Regional Centre of Advanced Technologies and Materials, Department of Analytical Chemistry, Faculty of Science, Palacky University Olomouc

${ }^{e}$ Department of Medical Chemistry and Biochemistry, Faculty of Medicine and Dentistry, Palacky University Olomouc Corresponding author: Vlastimil Masek, e-mail:v.masek@gmail.com

\section{INTRODUCTION}

Liver microsomal cytochromes P450 (P450s) play a very important role in the process of environmental chemical (xenobiotics) biotransformation as these heme-containing enzymes are responsible for more than one-half of known pathways of drug metabolism in the liver and other organs ${ }^{1}$. P450s form a superfamily of enzymes localized in the liver, lung, gastrointestinal tract, brain, heart, and in other tissues ${ }^{2}$. Within the group of liver microsomal P450s, nine forms (CYP1A2, CYP2A6, CYP2B6, CYP2C8, CYP2C9, CYP2C19, CYP2D6, CYP2E1, and CYP3A4) are active in the metabolism of more than $90 \%$ reactions catalyzed by these enzymes. The need for studies on the interaction of P450s with newly designed and synthesized compounds is linked to clinical application and to the fact that many drugs can be transformed by these enzymes to either less active or more active molecules. There is also possible competition of drug for these proteins causing drug interactions leading to increasing the toxic levels of the respective drugs ${ }^{3}$.

The anticancer activity of cisplatin (cis-diamminedichloridoplatinum(II)) has been known for more than
40 years ${ }^{4}$ and during this period a plethora of analogous compounds have been synthesized ${ }^{5}$ with the aim of enhancing the cytotoxic effect of the already applied substances, reduce their toxicity, and/or increase their ability to overcome the resistance of various tumors to the action of cisplatin or its analogues. The therapeutic activity of these compounds is mainly based on the covalent modification of the DNA molecule. There is much evidence on the formation of various types of covalent DNA adducts and their influence e.g. on DNA replication ${ }^{6}$. The platinum complexes were later followed by the complexes of other transition metals (e.g. ruthenium ${ }^{7}$ ), however, no such compound has been approved for clinical use to date.

Carboplatin (cis-diammine-cyclobutane-1,1' '-dicarboxylatoplatinum(II)) and oxaliplatin (1,2-diaminocyclohexane-oxalatoplatinum(II)) are more recent analogs exhibiting generally lower or less severe toxicity. Their use is increasing as in some indications they represent an alternative to cisplatin or exhibit effects unattainable for cisplatin (e.g. oxaliplatin in treatment of colorectal cancer) $\left(\right.$ ref. $\left.^{8}\right)$.

2-(1-Ethyl-2-hydroxyethylamino)-N6-(benzyl)-9isopropyladenine (Roscovitine; Ros) is a substance derived 
from a plant hormone N6-(benzyl)adenine (6-benzylaminopurine) (ref. ${ }^{9}$ ). Roscovitine belongs to the group of adenine-based cyclin-dependent kinase (CDK) inhibitors and this compound was successfully tested in vivo on patients with non-small cell lung cancer ${ }^{10,11}$. CDKs are core components of the cell cycle machinery that govern the transition between phases during cell cycle progression and currently represent one of the alternative enzyme groups with potential to be a target for anticancer therapy ${ }^{12,13}$.

A large group of complexes which combine in their structures diverse transition metals with variously substituted N6-(benzyl)adenine derivatives as ligands have been synthesized and tested for anticancer activity ${ }^{14-20}$. One of the most recently reported ${ }^{21}$ group of complexes involves the platinum(II) oxalato (ox) complexes $\left[\mathrm{Pt}(\mathrm{ox})(\mathrm{Ros})_{2}\right] \cdot 3 / 4 \mathrm{H}_{2} \mathrm{O}(1),\left[\mathrm{Pt}(\mathrm{ox})(2 \mathrm{OMeRos})_{2}\right] \cdot \mathrm{H}_{2} \mathrm{O}$ (2), $\left[\mathrm{Pt}(\mathrm{ox})(3 \mathrm{OMeRos})_{2}\right] \cdot 1 / 2 \mathrm{H}_{2} \mathrm{O}$ (3) and $[\mathrm{Pt}(\mathrm{ox})$ (4OMeRos) $\left.)_{2}\right] \cdot 3 / 4 \mathrm{H}_{2} \mathrm{O}$ (4) containing Roscovitine (Ros) and its benzyl-substituted analogues (i.e. 2-(1-ethyl2-hydroxyethylamino)-N6-(2-methoxybenzyl)-9-isopropyladenine (2OMeRos), 2-(1-ethyl-2-hydroxyethylamino) N6-(3-methoxybenzyl)-9-isopropyladenine (3OMeRos) and 2-(1-ethyl-2-hydroxyethylamino)-N6-(4-methoxybenzyl)9-isopropyladenine (4OMeRos)) as N-donor carrier ligands (Fig. 1). These complexes showed moderate $\left(\mathrm{IC}_{50}\right.$ ranged from 10.8 to $34.4 \mu \mathrm{M}$ ) and in most cases higher, as compared with cisplatin and oxaliplatin, in vitro cytotoxic activity against cisplatin sensitive (A2780) and resistant (A2780cis) ovarian carcinoma, malignant melanoma (G-361), lung carcinoma (A549), cervix epitheloid carcinoma (HeLa), breast adenocarcinoma (MCF7) and osteosarcoma (HOS) human cancer cell lines. Moreover, the representative complex 1 was not hepatotoxic up to a concentration of $50.0 \mu \mathrm{M}$, as observed on the primary cultures of human hepatocytes. These published ${ }^{21}$ results favored the complexes 1-4 for further biological studies, such as in vivo experiments on mouse L1210 leukemia model (unpublished results) or the present reported interaction with human liver microsomal P450s.

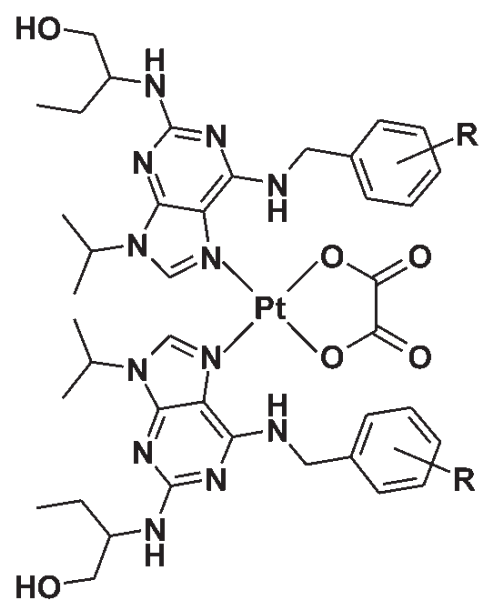

Fig. 1. General structural formula of studied complexes, where $\mathrm{R}=\mathrm{H}$ for complex (1); $\mathrm{R}=2$-methoxy for (2); $\mathrm{R}=3$-methoxy for (3); $\mathrm{R}=4$-methoxy for (4).

\section{MATERIALS AND METHODS}

\section{Chemicals}

Complexes 1-4 were prepared as described in detail previously ${ }^{21}$. For determination of CYP activities, chlorzoxazone, 6-hydroxychlorzoxazone, diclofenac, 4-hydroxydiclofenac, bufuralol, 6-hydroxybufuralol and $6 \beta$-hydroxytestosterone were supplied by Cerilliant Corporation (Round Rock, Texas, USA). P450-Glo ${ }^{\circledR}$ substrates luciferin ME (luciferin-6' methyl ether), luciferin $\mathrm{H}$ ( $6^{\prime}$-deoxyluciferin) and luciferin BE (luciferin-6' benzyl ether) for evaluation of CYP2C8, CYP2C9 and CYP3A4 activities by luminescence spectrometry were products of Promega (Madison, Wisconsin, USA) obtained through East Port (Prague, Czech Republic). 7-ethoxy-4-(trifluoromethyl)coumarin was supplied by Fluka (Buchs, Switzerland). Cryopreserved human liver microsomes (pooled) were purchased from Advancell (Barcelona, Spain). Microsomes were obtained by approval of the local Ethics Committee and in accordance with the ethic regulations of the country of origin (Spain). They were from 5 males and 5 females with protein content $38.4 \mathrm{mg} / \mathrm{mL}$; the CYP1A2, CYP2A6, CYP2B6, CYP2C9, CYP2E1 and CYP3A4 enzyme activities are accessible at the Advancell web site (www.advancell.net, batch reference 102091201). All other chemicals were supplied by Sigma Aldrich (Prague, Czech Republic).

\section{Determination of CYP activities}

Activities of individual CYP forms were measured according to published protocols. All the tested microsomal CYP activities and corresponding methods of specific product detection are listed in the Table 1 .

The stock solutions of complexes 1-4 in $N, N^{\prime}-$ dimethylformamide (DMF) were prepared before each CYP activity assay. The concentration of Pt in stock solutions was $20 \mathrm{mM}$ and was verified using ICP-MS (7000x Series, Agilent Technologies, USA). The stock solutions of the tested drugs were added to reaction mixtures to obtain the desired final concentration which covered two orders of magnitude, from $1 \mu \mathrm{M}$ to $100 \mu \mathrm{M}$. No drug was added to the control sample, only DMF.

Final incubation mixture volumes were: CYP1A2, CYP2A6 and CYP2B6, $100 \mu \mathrm{L}$; CYP2C8, $100 \mu \mathrm{L}$; CYP2C9, 100 and $50 \mu \mathrm{L}$ for diclofenac or 6 '-deoxyluciferin as substrates; CYP2C19, and CYP2D6, $200 \mu \mathrm{L}$; CYP2E1, $500 \mu \mathrm{L}$; CYP3A4 activities, $500 \mu \mathrm{L}$ for testosterone and $50 \mu \mathrm{L}$ for luciferin derivative as substrate. The final concentrations of microsomal P450 were as follows: CYP1A2, CYP2A6 and CYP2B6, $0.35 \mu \mathrm{M}$; CYP2C8, $1.20 \mu \mathrm{M}$; CYP2C9, $0.18 \mu \mathrm{M}$ and $0.68 \mu \mathrm{M}$ for diclofenac or 6 '-deoxyluciferin as substrates; CYP2C19, $0.25 \mu \mathrm{M}$; CYP2D6, $0.35 \mu \mathrm{M}$; CYP2E1, $0.16 \mu \mathrm{M}$; CYP3A4 activities, $0.14 \mu \mathrm{M}$ for testosterone and $1.20 \mu \mathrm{L}$ for luciferin derivative as substrate. The reaction mixtures of all CYP activities tested were buffered by $75 \mathrm{mM}$ K-phosphate buffer, $\mathrm{pH} 7.4$.

For each enzyme assay, a preliminary experiment was done to determine the $\mathrm{K}_{\mathrm{M}}$ and $\mathrm{V}_{\max }$ for a given enzyme 
reaction and to obtain the values of substrate concentrations suitable for the inhibition experiments (as a rule, substrate concentration was chosen in the range corresponding to the value of the $\mathrm{K}_{\mathrm{M}}$ ). Inhibition experiments were routinely performed with up to seven concentrations of the tested drug. As a rule, inhibition experiments with known reference inhibitors were implemented in cases where a significant degree of inhibition was presumed, namely, with sulfaphenazole (CYP2C9) (ref. ${ }^{22}$ ), methoxsalen (CYP2A6) $\left(\right.$ ref. $^{23}$ ), diethyldithiocarbamate (CYP2E1) (ref.,24), 3-isopropenyl-3-methyldiamantane (CYP2B6) (ref. ${ }^{25}$ ), and ketoconazole (CYP3A4) (ref. ${ }^{2}$ ). Selection of e established inhibitors was based on the data from the literature.

A TECAN Infinite M200 microplate reader (Tecan Austria, Vienna, Austria) was used for detection of the fluorescence- and luminescence-based assays. HPLC analyses were performed using the Dionex UltiMate 3000 system (Thermo Scientific brand).

Inhibition of individual CYP activities by complexes 1-4 was in all cases evaluated by plotting the respective remaining activity against the inhibitor concentration; as a rule, the results were expressed as the means of two to five independent determinations with the difference between duplicates being lower than $15 \%$.

When an inhibition was pronounced, the $\mathrm{K}_{\mathrm{i}}$ values were determined from Dixon plots with three substrate concentrations used (corresponding to $0.5 \mathrm{~K}_{\mathrm{M}}, \mathrm{K}_{\mathrm{M}}$ and
$2 \mathrm{~K}_{\mathrm{M}}$ ). To acquire information on the mechanism of inhibition, both Dixon and Lineweaver-Burk plots were used ${ }^{26}$.

To analyze the course of the enzyme kinetics, parameters of enzyme kinetics $\left(\mathrm{K}_{\mathrm{M}}, \mathrm{V}_{\text {max }}\right)$ as well as the intercepts of the respective plots were obtained using the Sigma Plot 8.0.2 (SPSS, Chicago, Illinois, USA) and GraphPad Prism 5 (GraphPad Software, San Diego, California, USA) scientific graphing software.

\section{RESULTS AND DISCUSSION}

Four oxaliplatin derivatives were studied: ([ $\mathrm{Pt}(\mathrm{ox})$ (Ros) $\left.)_{2}\right] \cdot 3 / 4 \mathrm{H}_{2} \mathrm{O}$ (1), [Pt(ox)(2OMeRos) $\left.{ }_{2}\right] \cdot \mathrm{H}_{2} \mathrm{O}(2),[\mathrm{Pt}($ ox $)$ (3OMeRos) $\left.)_{2}\right] \cdot 1 / 2 \mathrm{H}_{2} \mathrm{O}(3)$ and $\left[\mathrm{Pt}(\mathrm{ox})(4 \mathrm{OMeRos})_{2}\right] \cdot 3 / 4 \mathrm{H}_{2} \mathrm{O}$ (4)) and the activities of nine forms of CYP enzymes present in human liver microsomes (CYPs 1A2, 2A6, 2B6, 2C8, 2C9, 2C19, 2D6, 2E1, 3A4). The results show that within complex concentration ranges up to $10 \mu \mathrm{M}$, corresponding approximately to levels attainable in human plasma $^{33}$, all CYP activities were affected only slightly (with effect of inhibition less than 25\%) except CYP3A4 activity, which shows inhibition 33-47\% (Fig. 2A).

To obtain information on whether complexes at higher concentrations are able to inhibit CYP enzymes in a more pronounced extent, compounds 1-4 werealso tested for ten times higher concentration equal to $100 \mu \mathrm{M}$. Here all for CYP forms are affected markedly, (inhibition typically

Table 1. The list of CYP activities tested and references to corresponding methods of individual CYP activity product detection.

\begin{tabular}{|c|c|c|c|}
\hline CYP450 & CYP activity & Detection & Reference \\
\hline \multirow[t]{2}{*}{$1 \mathrm{~A} 2$} & 7-ethoxyresorufin O-deethylation & fluorescence & 27 \\
\hline & 7-ethoxyresorufin O-deethylation & HPLC & 27 \\
\hline $2 \mathrm{~A} 6$ & coumarin 7-hydroxylation & fluorescence & 27 \\
\hline \multirow[t]{2}{*}{ 2B6 } & $\begin{array}{l}\text { 7-ethoxy-4-(trifluoromethyl) coumarin } \\
\text { O-deethylation }\end{array}$ & fluorescence & 28 \\
\hline & $\begin{array}{l}\text { 7-ethoxy-4-(trifluoromethyl) coumarin } \\
\text { O-deethylation }\end{array}$ & HPLC & 29 \\
\hline $2 \mathrm{C} 8$ & $\begin{array}{l}\text { luciferin-6' methyl ether demethylation } \\
\text { (P450-Glo substrate) }\end{array}$ & luminescence & $\begin{array}{l}\text { Tech. Bulletin No } 325 \\
\text { www.promega.com }\end{array}$ \\
\hline $2 \mathrm{C} 9$ & $\begin{array}{l}\text { diclofenac } 4 \text { '-hydroxylation } \\
6 \text { '-deoxyluciferin hydroxylation } \\
\text { (P450-Glo substrate) }\end{array}$ & $\begin{array}{l}\text { HPLC } \\
\text { luminescence }\end{array}$ & $\begin{array}{l}30 \\
\text { Tech. Bulletin No } 325 \\
\text { www.promega.com }\end{array}$ \\
\hline $2 \mathrm{C} 19$ & (S)-mephenytoin 4 '-hydroxylation & HPLC & $\begin{array}{l}\text { www.cypex.co.uk } \\
\text { Cypex 2C19 QC assays }\end{array}$ \\
\hline 2D6 & bufuralol 1 '-hydroxylation & HPLC & 30 \\
\hline $2 \mathrm{E} 1$ & chlorzoxazone 6-hydroxylation & HPLC & 31 \\
\hline $3 \mathrm{~A} 4$ & $\begin{array}{l}\text { testosterone } 6 \beta \text {-hydroxylation } \\
\text { luciferin-6' benzyl ether debenzylation } \\
\text { (P450-Glo substrate) }\end{array}$ & $\begin{array}{l}\text { HPLC } \\
\text { luminescence }\end{array}$ & $\begin{array}{l}32 \\
\text { Tech. Bulletin No } 325 \\
\text { www.promega.com }\end{array}$ \\
\hline
\end{tabular}




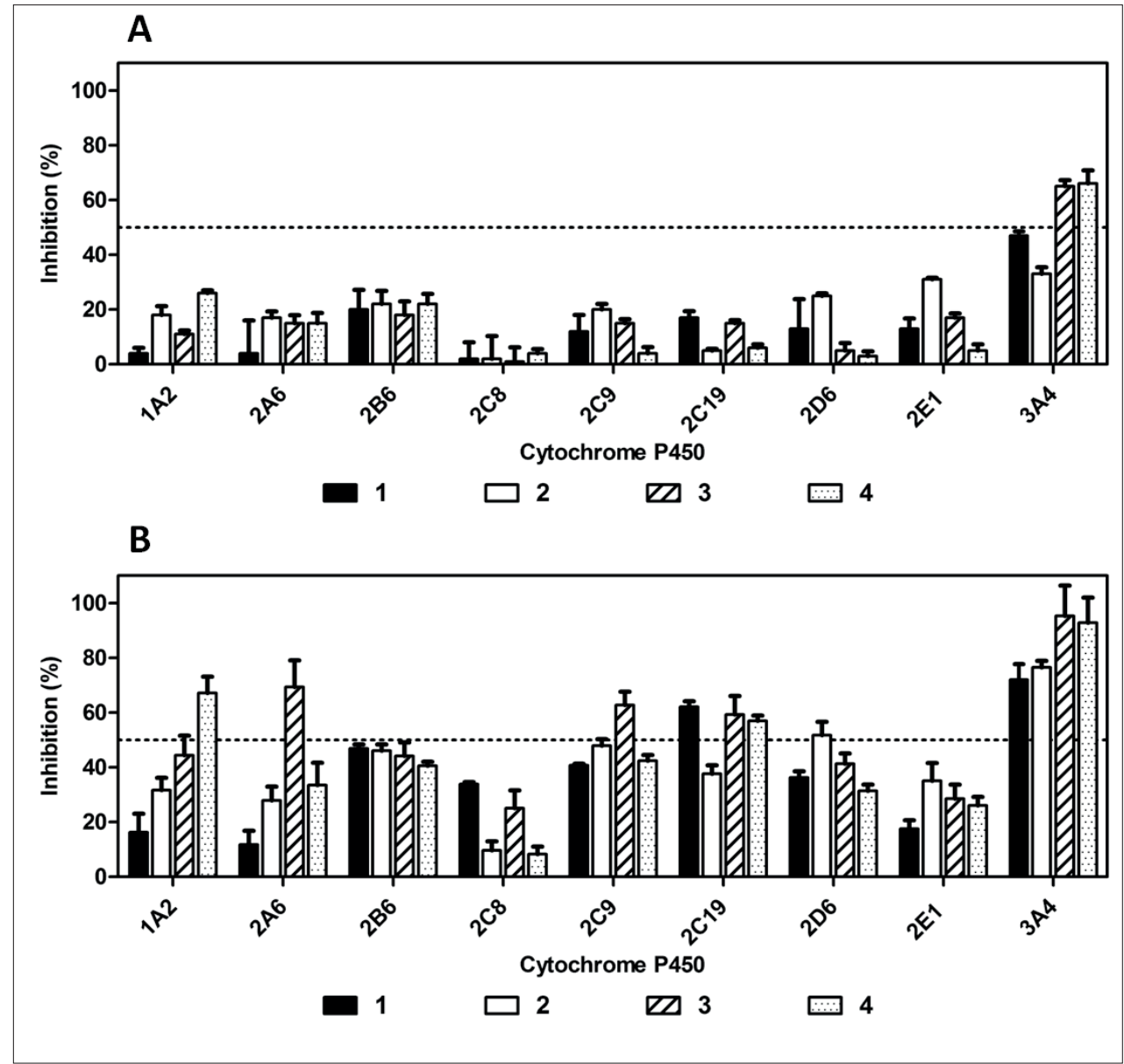

Fig. 2. Overview of inhibition rates of CYP activities by complexes 1-4 at $10 \mu \mathrm{M}(\mathrm{A})$ and $100 \mu \mathrm{M}$ (B) concentration. Results expressed as extent of inhibition that is $100 \%$, full inhibition. Individual activities determined as described in Materials and methods. Mean and standard deviation values are shown.

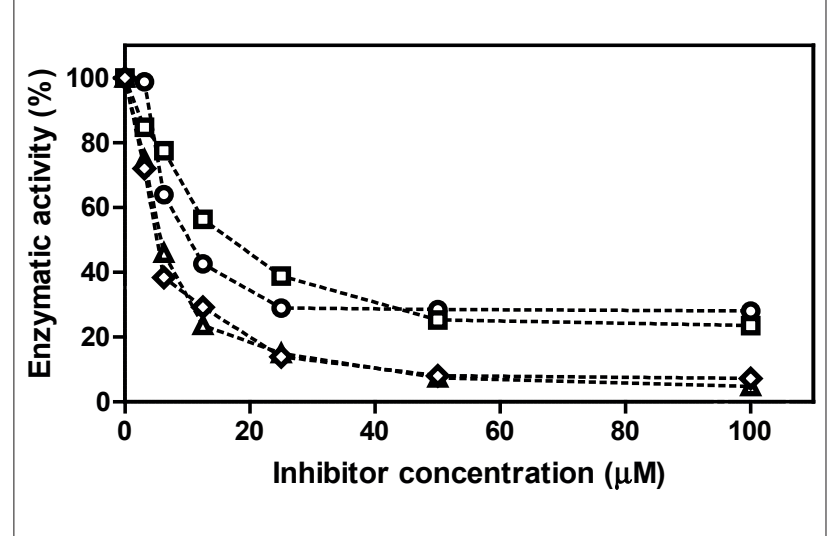

Fig. 3. Effect of individual complexes (circles (1), squares (2), triangles (3) and diamonds (4)) on specific activity of CYP3A4, testosterone 6 $\beta$-hydroxylation, in a dose-dependent manner. Concentrations of $1-4$ in the reaction mixture were 0 , $3,6,12,25,50$ and $100 \mu \mathrm{M}$.

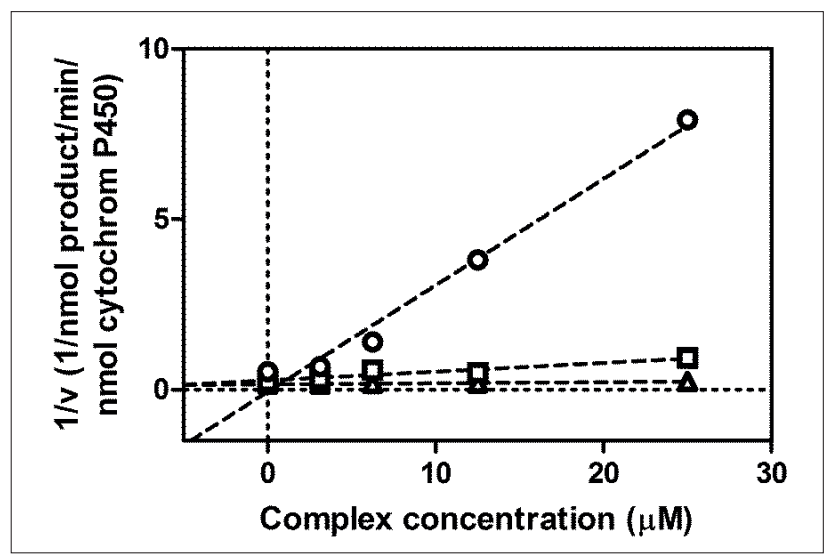

Fig. 4. Dixon plot at lower range of complex[ $\mathrm{Pt}(\mathrm{ox})$ $\left.(\text { Ros })_{2}\right] \cdot 3 / 4 \mathrm{H}_{2} \mathrm{O}$ (1) concentrations for inhibition of CYP3A4, testosterone $6 \beta$-hydroxylation, at three substrate concentrations ( $50 \mu \mathrm{M}$, squares; $100 \mu \mathrm{M}$, triangles; $200 \mu \mathrm{M}$, circles). 1/v, reciprocal velocity. 
between $20-50 \%$ ). At $100 \mu \mathrm{M}$ concentration, similar to the effects observed at $10 \mu \mathrm{M}$ level, the most prominent effect was observed at the CYP3A4 form which was nearly completely inhibited with complexes 3 and 4 (inhibition 95\% and 93\% respectively), inhibition of CYP3A4 with complexes 1 and 2 was $72 \%$ and $77 \%$ (Fig. 2B).

In most cases, the inhibition even at high drug concentration $(100 \mu \mathrm{M})$ hardly reaches $50 \%$. The most prominent inhibition even at $10 \mu \mathrm{M}$ concentration was observed for CYP3A4. This is apparently due to the fact that the active site of this enzyme is able to accommodate bulky substrates (as e.g. macrolide antibiotics and steroids) (ref. ${ }^{34-37}$ ).

We reported earlier ${ }^{38}$ that oxaliplatin exhibits only negligible effect on P450s even at very high concentration. With this compound, we observed the inhibition of CYP2C9 enzyme however only by about $20 \%$ and at extremely high concentration of the drug $(400 \mu \mathrm{M})$. Hence, this study should also show whether the introduction of roscovitine-based $\mathrm{N}$-donor ligand to the parent drug (oxaliplatin) will affect the complex-P450s interaction. Radical changes in the manner of interaction with P450s, i.e. that the complexes studied here inhibit the CYP enzymes,are probably related to the fact that relatively polar oxaliplatin does not enter the active site of CYP enzymes, with the exception of $\mathrm{CYP} 2 \mathrm{C} 9$. On the other hand roscovitine and its derivatives are less polarand possibly interact with CYP enzymes to a greater extent.

Apparently the inhibition patterns are determined mainly by the properties of the active site of the respective CYP enzyme. The position of the methoxy group (none (1); 2-methoxybenzyl (2); 3-methoxybenzyl (3); 4-methoxybenzyl (4)) does not seem to affect the inhibition of CYP3A4 activity in a systematic manner.

Experimental data obtained for CYP3A4 inhibition (Fig. 3) were analyzed by Dixon ${ }^{26,39}$ and Lineweaver-Burk ${ }^{26}$ plots to evaluate the possible mechanisms of enzyme inhibition.

However the results did not yield unambiguous answer as the courses of Dixon and Lineweaver-Burk plots did not correlate well with standard diagnostic courses of these plots described for individual inhibition mechanisms as at higher concentrations the results are apparently influenced by the strong binding of compounds tested, to enzyme proteins. Analysis of data reduced to lower range of complex concentrations (as represented in Fig. 4 for complex 1) corresponds to partially noncompetitive mechanism of inhibition.

\section{CONCLUSION}

Complexes 1-4 inhibit CYP3A4 activity even at clinically relevant concentration. This could be a serious drawback for the use of these compounds in clinical practice as the majority of drugs are metabolized by this enzyme. This facilitates their elimination or, in some cases of pro-drugs, to formation of pharmacologically active species.

\section{ACKNOWLEDGEMENT}

The authors gratefully thank the Czech Academy of Sciences (GAČR projects P208/10/P466 and P207/11/0841), student grants from Palacky University Olomouc LF-2013-007 and PrF-2013-030, Operational Program Research and Development for Innovations - European Regional Development Fund (projects CZ.1.05/2.1.00/01.0030 and CZ.1.05/2.1.00/03.0058), and Operational Program Education for Competitiveness - European Social Fund (CZ.1.07/2.3.00/20.0017) of the Ministry of Education, Youth and Sports of the Czech Republic.

Author contributions: VM, PS, ZT, EA: study design; VM, PS: manuscript writing; VM, MH, MM, DM: data collection and analysis; VM, ZT, EA: data interpretation; PS: compounds synthesis; all authors: manuscript revision.

Conflict of interest statement: The authors state that there are no conflicts of interest regarding the publication of this article.

\section{REFERENCES}

1. Anzenbacher P, Anzenbacherova E. Cytochromes P450 and metabolism of xenobiotics. Cellular and Molecular Life Sciences 2001;58(56):737-47.

2. Guengerich FP. Human cytochrome P450 Enzymes. In: Ortiz de Montellano PR, editor. Cytochrome P450. Structure, mechanism and biochemistry. New York: Kluwer Academic/Plenum; 2006. p. 377-530.

3. Bachmann KA, Lewis JD, Fuller MA, Bonfiglio MF, Drug Interactions Handbook.Hudson, OH: 2nd Edition. Lexi-Comp; 2004.

4. Rosenberg B, Vancamp L, Trosko JE, Mansour VH. Platinum Compounds - a New Class of Potent Antitumour Agents. Nature 1969;222(5191):385-6.

5. Gielen M, Tiekink ERT, Metallotherapeutic Drugs and Metal-Based Diagnostic Agents: The Use of Metals in Medicine.London: 1st. John Wiley \& Sons, Ltd; 2005.

6. Brabec V. DNA modifications by antitumor platinum and ruthenium compounds: Their recognition and repair. Progress in Nucleic Acid Research and Molecular Biology 2002;71:1-68.

7. Kostova I. Ruthenium complexes as anticancer agents. Current Medicinal Chemistry 2006;13(9):1085-107.

8. Chabner B, Amrein P, Druker B, Michaelson M, Mitsiades C, Goss P, al. e. Antineoplastic agents. In: Brunton L; Lazo J; Parker K, editors. Goodman and Gilman's The pharmacological basis of therapeutics. New York: McGraw-Hill; 2006. p. 1315-1403.

9. Davies PJ, Plant hormones.Dordrecht: third. Springer; 1997.

10. Meijer L, Borgne A, Mulner O, Chong JPJ, Blow JJ, Inagaki N, Inagaki M, Delcros JG, Moulinoux JP. Biochemical and cellular effects of roscovitine, a potent and selective inhibitor of the cyclin-dependent kinases cdc2, cdk2 and cdk5. European Journal of Biochemistry 1997;243(1-2):527-36.

11. Benson C, Kaye S, Workman P, Garrett M, Walton M, de Bono J. Clinical anticancer drug development: targeting the cyclin-dependent kinases. British Journal of Cancer 2005;92(1):7-12.

12. Diaz-Padilla I, Siu LL, Duran I. Cyclin-dependent kinase inhibitors as potential targeted anticancer agents. Investigational New Drugs 2009;27(6):586-94.

13. Ljungman M, Paulsen MT. The cyclin-dependent kinase inhibitor roscovitine inhibits RNA synthesis and triggers nuclear accumulation of p53 that is unmodified at Ser15 and Lys382. Molecular Pharmacology 2001;60(4):785-9.

14. Dvorak L, Popa I, Starha P, Travnicek Z. In Vitro Cytotoxic-Active Platinum(II) Complexes Derived from Carboplatin and Involving Purine Derivatives. European Journal of Inorganic Chemistry 2010;22):3441-8. 
15. Starha P, Popa I, Travnicek Z. Palladium(II) oxalato complexes involving N6-(benzyl)-9-isopropyladenine-based N-donor carrier ligands: Synthesis, general properties, $\mathrm{H}-1, \mathrm{C}-13$ and $\mathrm{N}-15\{\mathrm{H}-1\}$ NMR characterization and in vitro cytotoxicity. Inorganica Chimica Acta 2010;363(7):1469-78.

16. Starha P, Popa I, Travnicek Z, Vanco J. N6-Benzyladenosine Derivatives as Novel N-Donor Ligands of Platinum(II) Dichlorido Complexes. Molecules 2013;18(6):6990-7003.

17. Travnicek Z, Starha P, Vanco J, Silha T, Hosek J, Suchy P, Prazanova G. Anti-inflammatory Active Gold(I) Complexes Involving 6-Substituted-Purine Derivatives. Journal of Medicinal Chemistry 2012;55(10):4568-79.

18. Travnicek Z, Szucova L, Popa I. Synthesis, characterization and assessment of the cytotoxic properties of cis and trans-[Pd( $\mathrm{L})(2) \mathrm{Cl}-2]$ complexes involving 6-benzylamino-9-isopropylpurine derivatives. Journal of Inorganic Biochemistry 2007;101(3):477-92.

19. Vrzal R, Starha P, Dvorak Z, Travnicek Z. Evaluation of in vitro cytotoxicity and hepatotoxicity of platinum(II) and palladium(II) oxalato complexes with adenine derivatives as carrier ligands. Journal of Inorganic Biochemistry 2010;104(10):1130-2.

20. Liskova B, Zerzankova L, Novakova O, Kostrhunova H, Travnicek Z, Brabec V. Cellular Response to Antitumor cis-Dichlorido Platinum(II) Complexes of CDK Inhibitor Bohemine and Its Analogues. Chemical Research in Toxicology 2012;25(2):500-9.

21. Travnicek Z, Starha P, Popa I, Vrzal R, Dvorak Z. Roscovitine-based CDK inhibitors acting as $\mathrm{N}$-donor ligands in the platinum(II) oxalato complexes: Preparation, characterization and in vitro cytotoxicity. European Journal of Medicinal Chemistry 2010;45(10):4609-14.

22. Brown HS, Galetin A, Hallifax D, Houston JB. Prediction of in vivo drug-drug interactions from in vitro data - Factors affecting prototypic drug-drug interactions involving CYP2C9, CYP2D6 and CYP3A4. Clinical Pharmacokinetics 2006;45(10):1035-50.

23. Kharasch ED, Hankins DC, Taraday JK. Single-dose methoxsalen ef fects on human cytochrome P-450 2A6 activity. Drug Metabolism and Disposition 2000;28(1):28-33.

24. Bourrie M, Meunier V, Berger Y, Fabre G. Cytochrome P450 isoform inhibitors as a tool for the investigation of metabolic reactions catalyzed by human liver microsomes. Journal of Pharmacology and Experimental Therapeutics 1996;277(1):321-32.

25. Stiborova M, Borek-Dohalska L, Hodek P, Mraz J, Frei E. New selective inhibitors of cytochromes P4502B and their application to antimutagenesis of tamoxifen. Archives of Biochemistry and Biophysics 2002;403(1):41-9.

26. Segel IH, Enzyme Kinetics. Behavior and Analysis of Rapid Equilibrium and Steady State Enzyme Systems.New York: WileyInterscience; 1993.

27. Waxman DJ, Chang TKH. Spectrofluorometric analysis of CYP2A6catalyzed coumarin 7 hydroxylation. In: Phillips IR; Shephard EA, editors. Cytochrome P450 protocols. Totowa (NJ): Humana Press; 1998. p. 111-116.

28. Donato MT, Jimenez N, Castell JV, Gomez-Lechon MJ. Fluorescencebased assays for screening nine cytochrome P450 (P450) activities in intact cells expressing individual human P450 enzymes. Drug Metabolism and Disposition 2004;32(7):699-706.

29. Morse MA, Lu J. High-performance liquid chromatographic method for measurement of cytochrome P450-mediated metabolism of 7-ethoxy-4-trifluoromethylcoumarin. Journal of Chromatography B 1998;708(1-2):290-3.

30. Crespi CL, Chang TKH, Waxman DJ. Determination of CYP2C9catalyzed diclofenac 4'-hydroxylation by high-performance liquid chromatography. In: Phillips IR; Shephard EA, editors. Cytochrome P450 protocols. Totowa (NJ): Humana Press; 1998. p. 129-40.

31. Lucas D, Menez JF, Berthou F. Chlorzoxazone: An in vitro and in vivo substrate probe for liver CYP2E1. Cytochrome P450, Pt B 1996:272:115-23.

32. Guengerich FP, Martin MV, Beaune PH, Kremers $P$, Wolff $T$, Waxman DJ. Characterization of Rat and Human-Liver Microsomal Cytochrome-P-450 Forms Involved in Nifedipine Oxidation, a Prototype for Genetic-Polymorphism in Oxidative Drug-Metabolism. Journal of Biological Chemistry 1986;261(11):5051-60.

33. Brunton L, Lazo J, Parker K, Goodman and Gilman's The pharmacological basis of therapeutics. New York: McGraw-Hill; 2006.

34. Hendrychova T, Berka K, Navratilova V, Anzenbacher P, Otyepka M. Dynamics and Hydration of the Active Sites of Mammalian Cytochromes P450 Probed by Molecular Dynamics Simulations. Current Drug Metabolism 2012;13(2):177-89.

35. Williams PA, Cosme J, Vinkovic DM, Ward A, Angove HC, Day PJ, Vonrhein C, Tickle IJ, Jhoti H. Crystal structures of human cytochrome P450 3A4 bound to metyrapone and progesterone. Science 2004;305(5684):683-6.

36. Yano JK, Wester MR, Schoch GA, Griffin KJ, Stout CD, Johnson EF. The structure of human microsomal cytochrome P450 3A4 determined by X-ray crystallography to 2.05-angstrom resolution. Journal of Biological Chemistry 2004;279(37):38091-4

37. Johnson EF, Sansen S, Reynald RL, Yano JK, Schoch GA, Stout CD. Update on CYP crystal structures and applications. Drug Metabolism Reviews 2006;38:25.

38. Masek V, Anzenbacherova E, Machova M, Brabec V, Anzenbacher $P$. Interaction of antitumor platinum complexes with human liver microsomal cytochromes P450. Anti-Cancer Drugs 2009;20(5):30511.

39. Burlingham BT, Widlanski TS. An intuitive look at the relationship of K-i and IC50: A more general use for the Dixon plot. Journal of Chemical Education 2003;80(2):214-8. 